\title{
Bio-Logical Human Tissue Based Electronic Circuits - An Alternate to Drug Therapy for Sick-Man (A Perspective Visionary Concept)
}

Shiv Prasad Kosta ${ }^{1 *}$, Y P Kosta ${ }^{2}$, Mukta Bhatele ${ }^{3}$, Killol Pandya ${ }^{1}$, D Soni ${ }^{3}$, Avinash Gour ${ }^{3}$, Y M Dubey ${ }^{1}$, Bhavin Patel ${ }^{2}$, Harsh Mehta ${ }^{2}$ and Shakti Kosta ${ }^{4}$

${ }^{1}$ Charotar University of Science and Technology, Changa Ta-Petlad, Anand, Gujarat, India

${ }^{2}$ Department of Computer Science, Charotar University of Science and Technology, Changa Ta-Petlad, Anand, Gujarat, India

${ }^{3}$ Department of Computer Science, Gyan-Ganga College of Science and Technology, Jabalpur, M.P, India

${ }^{4}$ Shree Ram Institute of Science and Technology, Jabalpur, M.P, India

\begin{abstract}
Chemical drug based human disease healing $(\mathrm{CDBHDH})$ is well established methodology in Medical sciences. The Physician's drug (medicine) dose given to a sick man interacts through chemical reaction with the complex polluted drugs of the sick man which results in the normalization of the disturbed (sick man) ion profiles. In this communication we advocate for the first time creation of an appropriate human tissue based electronic circuit (HTBEC) inside the human body (at appropriate determined location) to normalize the prevailing disturbed ion profiles of sick man and thus HTBEC can act as alternate to CDBHDH in some cases. After review of our relevant reported work a few conceptually realizable HTBEC (digital/analog) to demonstrate the feasibility is presented.
\end{abstract}

Keywords: Human tissue; Digital/Analog circuit; Amplifier; Drug therapy; Ion profile

\section{Introduction}

The importance of human blood electronic circuit components and their application circuits towards Cyborg implant/engineering, manmachine interfacing, human disease detection and healing, artificial brain evolution etc. are now gradually emerging [1-5].

\section{The intuition (provoking thought)}

Scientifically, the normal human body functioning is due to the appropriate controlled dynamics of positive and negative ions of its tissues (blood, skin, nerves, intestine, muscle, capillaries etc.) and organs. From first order of approximation one can state that the status of human health heavily depends on the dynamics of its tissue/organ system's ion profiles. If by food intake or by environmental disturbances the man become sick then its ion profiles deteriorates. Customarily the Physician treats the sick man by giving external dose of chemical drugs which after biochemical reactions/interactions inside the human body brings back the deterioration in the ion profiles to zero and thus the man becomes normal. In this context we for the first time propose an alternate to CDBHDH by using HTBEC to normalize the disturbed ion profiles. This concept of HTBEC has excellent high technology impact towards detecting and healing of human diseases.

\section{How We Proceeded}

We realized first human tissue based memristor (2010), electronic diode (2010), electronic Transistor (2012), electronic skin transistor (2012),electronic digital circuit AND \& OR gates (2010), electronic IC Amplifier (April, 2013). Figures 1-6, depicts symbolically their configuration with characteristics.

\section{Biological resistance $R$ and capacitance $C$}

Human blood containing electrically charged particle ions under influence of external emf acquire dynamism and face collisions and thus manifest resistance R. Similarly the electrically charged dynamic ions of blood molecules/atoms which are distantly placed have dynamic emf field between them and thus manifest capacitance.

\section{Biological memristors network}

The first physical model of human blood liquid memristor was reported by us in April 2011 [1]. In Figure 1, three bio resistances (formed by probes $\mathrm{AB}, \mathrm{DC}, \mathrm{EF}$ ) are sequentially connected in series and later on in parallel (circuit configuration) respectively having voltage power supply and current measuring instrument Ammeter in the closed electronic circuit. Memristance characteristics (resistance retention for positive, and negative EMF modes, as well as nonlinear behavior of charge "Q" with elapsed for continuous flow of current time "t") first individually and subsequently in series and parallel networks were realized are shown in Charts $1 \mathrm{~A}, 1 \mathrm{~B}, 1 \mathrm{C}, 1 \mathrm{D}, 1 \mathrm{E}, 2,3,4 \mathrm{~A}$ and $4 \mathrm{~B}$ [3].

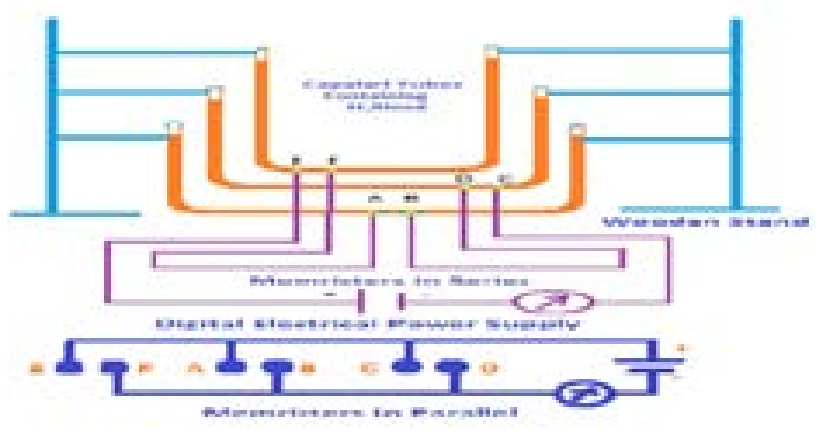

Figure 1: Experimental Layout of Human Blood Memristor Network [7].

*Corresponding author: Shiv Prasad Kosta, Charotar University of Science and Technology, Changa Ta-Petlad, Anand 388421, Gujarat, India, Tel: 91-942-641-9506; E-mail: drspkosta@yahoo.com

Received May 22, 2013; Accepted December 25, 2013; Published December 30,2013

Citation: Kosta SP, Kosta YP, Bhatele M, Pandya K, Soni D, et al. (2013) Bio-Logica Human Tissue Based Electronic Circuits - An Alternate to Drug Therapy for SickMan (A Perspective Visionary Concept). J Bioengineer \& Biomedical Sci 4: 127. doi: 10.4172/2155-9538.1000127

Copyright: ( 2013 Kosta SP, et al. This is an open-access article distributed under the terms of the Creative Commons Attribution License, which permits unrestricted use, distribution, and reproduction in any medium, provided the original author and source are credited. 
Citation: Kosta SP, Kosta YP, Bhatele M, Pandya K, Soni D, et al. (2014)Bio-Logical Human Tissue Based Electronic Circuits - An Alternate to Drug Therapy for Sick-Man (A Perspective Visionary Concept). J Bioengineer \& Biomedical Sci 3: 127. doi: 10.4172/2155-9538.1000127

Page 2 of 6

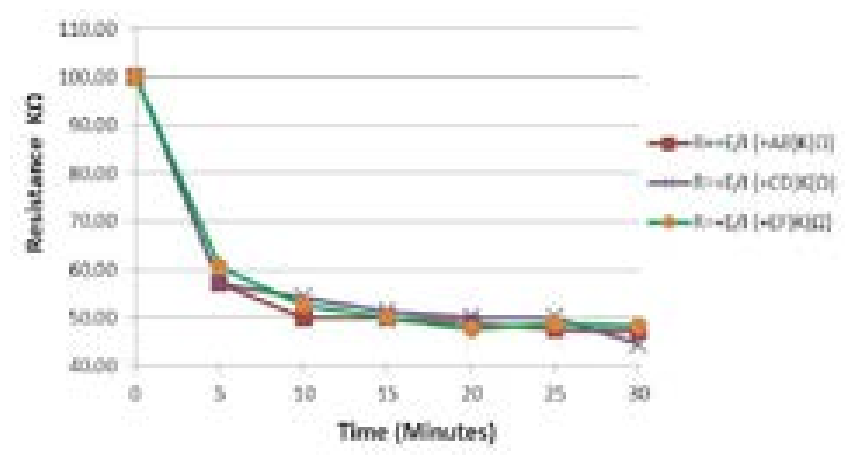

Chart 1A: Memristances $(R+K \Omega)$ variation of vs. time (minutes) for three individual memristors (for applied positive $\mathrm{E}=2 \mathrm{~V}$ ).

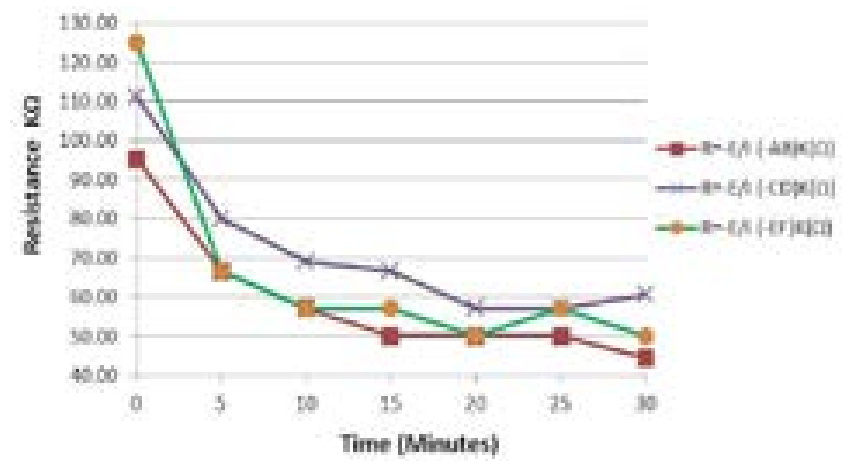

Chart 1B: Memristances $(R-K \Omega)$ variation of vs. time (minutes) for three individual memristors (for applied negative $\mathrm{E}=2 \mathrm{~V}$ ).

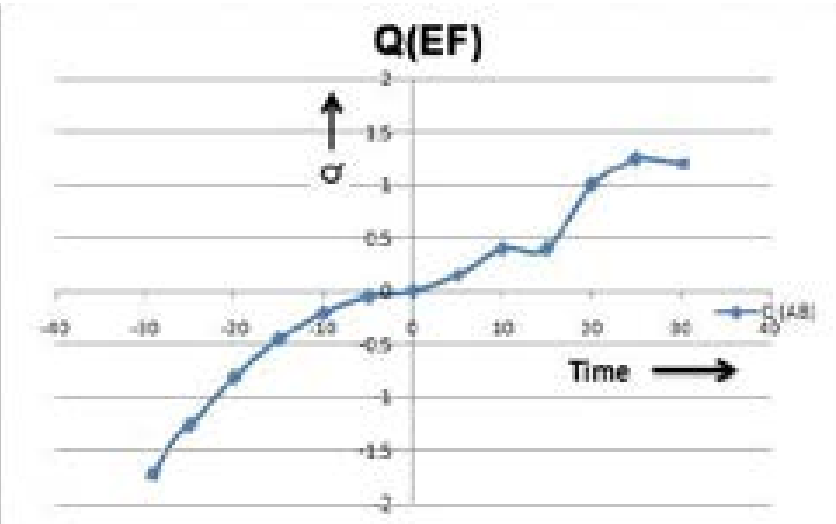

Chart 1C: Non Linearity for $E F(E+/=2 V)$.

\section{Biological human blood transistor}

Figure 2 depicts human blood (flowing) contained in narrow capillary tube (in the horizontal position) possess positive and negative ions $\mathrm{Na}^{+}, \mathrm{K}^{+}, \mathrm{Cl}^{-}, \mathrm{HCO}_{3} \mathrm{Mg}^{+}, \mathrm{Fe}^{+}$etc.. We inserted four metallic probes 1- 2- 3- 4 and appropriately connected them to input and output circuits incorporating voltage power supply and Ammeters. The four metallic probes depict biological transistor with two diodes connected in back to back configuration (terminal 2 and 3 are shorted and earthed to represent emitter). Input and output characteristics are depicted in Chart 5A \& 5B [5].

\section{Biological human skin diode/transistor}

Figure $3 \mathrm{~A}$ and $3 \mathrm{~B}$ depicts in a self-explanatory manner our reported realization of human skin based active devices Diode/Transistor with performance characteristics [Chart 6A, 6B and 7A, 7B] [5].

\section{Biological human blood based IC amplifier}

For the first time (Figure 5) human blood IC amplifier circuit is demonstrated. First the discrete (values of passive/active) electronic circuit components, resistances, capacitances and transistor along

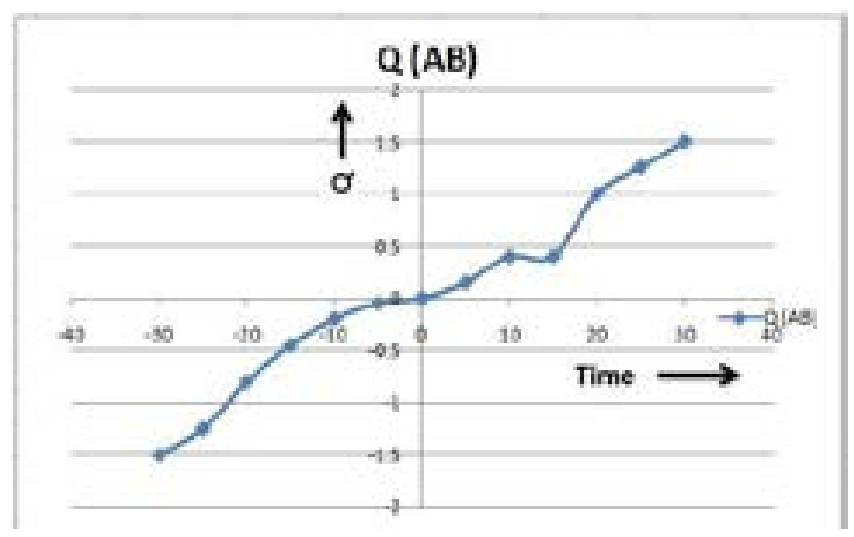

Chart 1D: Non Linearity for $A B(E+/=2 V)$.

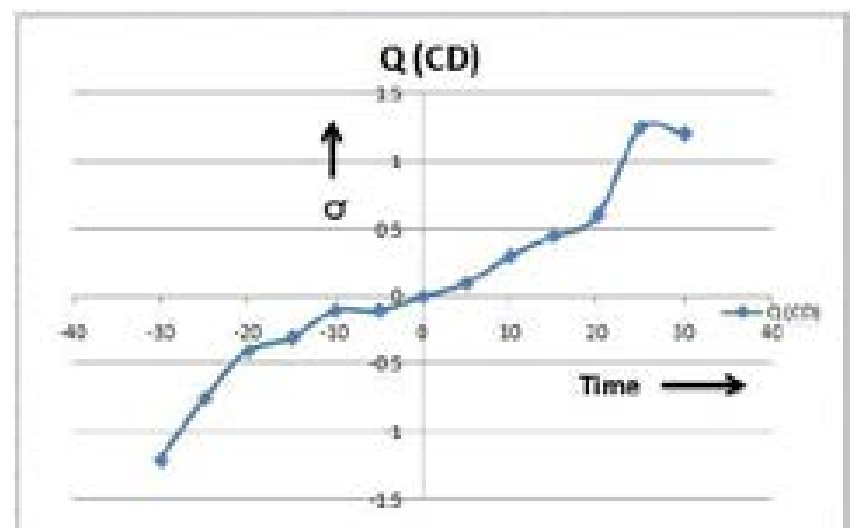

Chart 1E: Non Linearity for $C D(E+/=2 V)$.

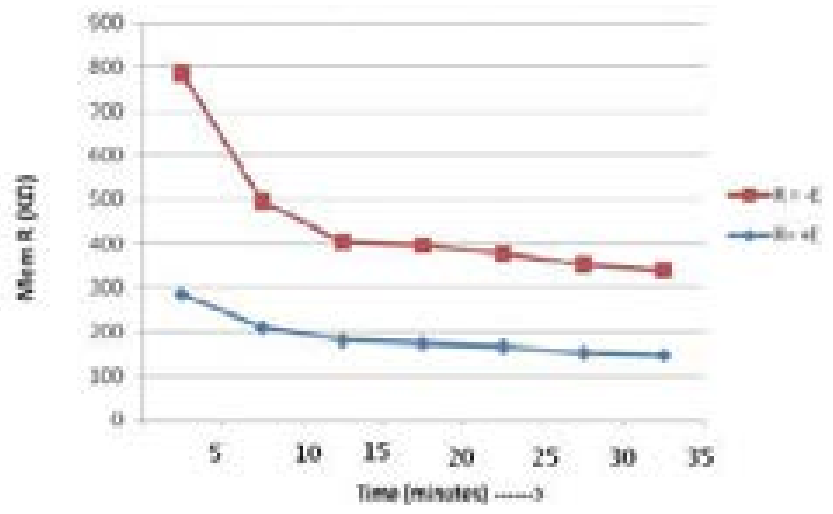

Chart 2: Memristors A-B,C-D,E-F in Series. 


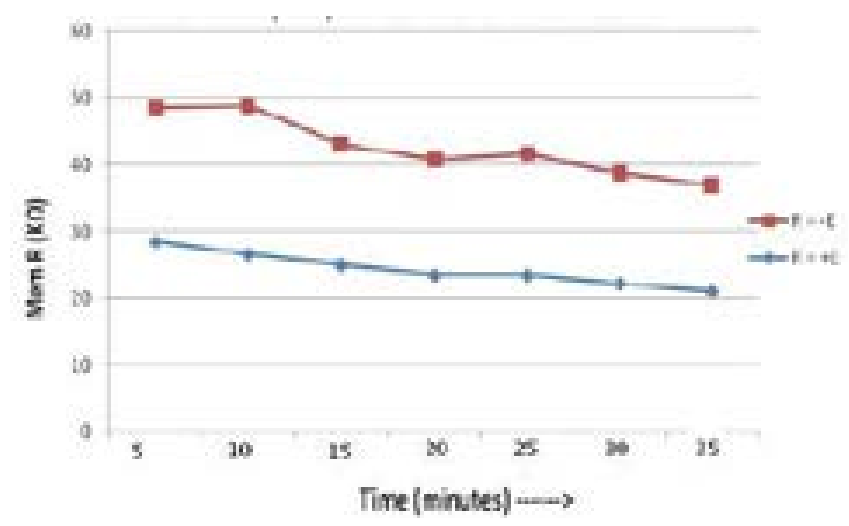

Chart 3: Memristors A-B,C-D, E-F in Parallel .

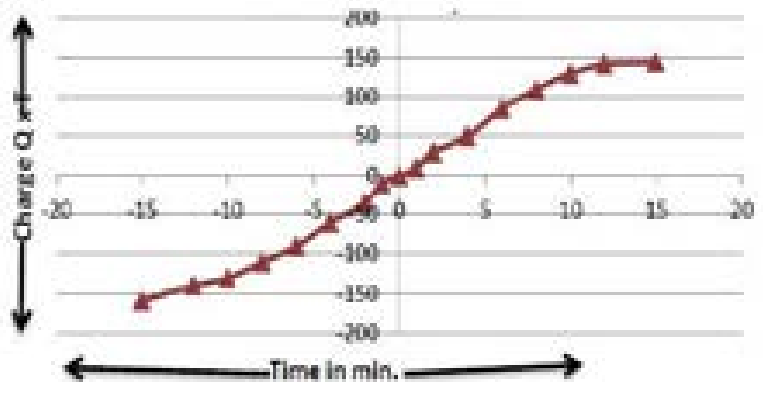

Chart 4A: Series circuit (continuous current flow) charge variation with time for $E=+/-2 V$.

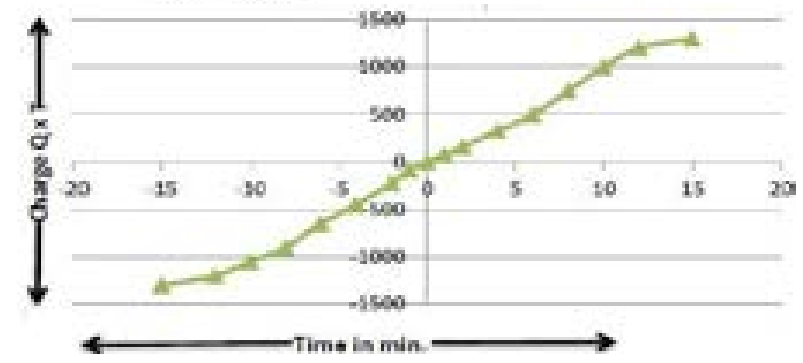

Chart 4B: Parallel circuit (continuous current flow) charge variation with time for $E=+/-2 V$.

with harness of theoretical circuit were configured and examined for amplifier characteristics. Later on in a glass flask filled with human blood the biological electronic circuit components of theoretical circuit (R1, R2, RC, RE, C1, C2 and Transistor) were realized by inserting metallic probes in the blood. The gain of the amplifier $\mathrm{v} / \mathrm{s}$ frequency is presented in Chart 8 [4].

\section{Biological human blood based digital biological OR/AND gates}

The biological digital circuits OR \& AND gates were realized as shown in Figure 6. Two diode probes A \& B were inserted in glass beaker containing blood. These two probes were then appropriately connected to the voltage power supply and resistance $(\mathrm{R}=2.2 \mathrm{~K} \Omega)$ to realize OR \& AND gates. Table 1 depicts the Boolean truth table (Logic) of realized OR/AND gates.

\section{The Research Study (Conceptual)}

We have realized human tissue based memristor (2010), electronic diode (2011), electronic transistor; analog and digital circuits referred above utilizing wire harness and thin inserted metallic probes. Now we propose to utilize nerves, blood vessel capillaries, bones, muscles, intestines, axon etc. as harness constituent elements. Scientifically it looks possible to develop the bio-logical electrical harness made from nerves, blood vessel capillaries, bones, muscles, intestines. Because all the human tissues (chemicals) contain electrically conducting positive and negative ions ( of inorganic/organic compound ) and hence if we can sort out insulation (electrically) problem among parallel or sideby-side running human tissues (bones, capillaries, nerves etc.), the creation of HTBEC at appropriate points/location inside human body is just feasible using expertise of Medical Surgeons. In this context we are proposing the following conceptual circuits which can be created inside the human body using expert surgery methodology.

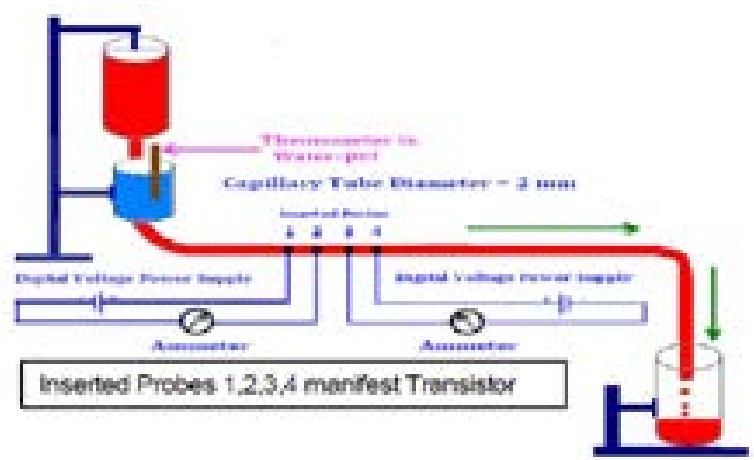

Figure 2: Human blood based transistorc onfiguration [7].

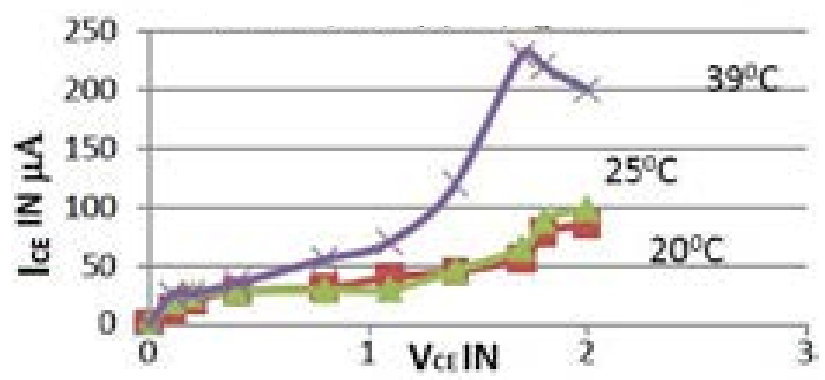

Chart 5A: Input charact (flow mode) probes spacing $\mathrm{d}=1.1 .2 .1,60 \mathrm{drops} /$ $\min , \mathrm{VCE}=3.0 \mathrm{~V}$

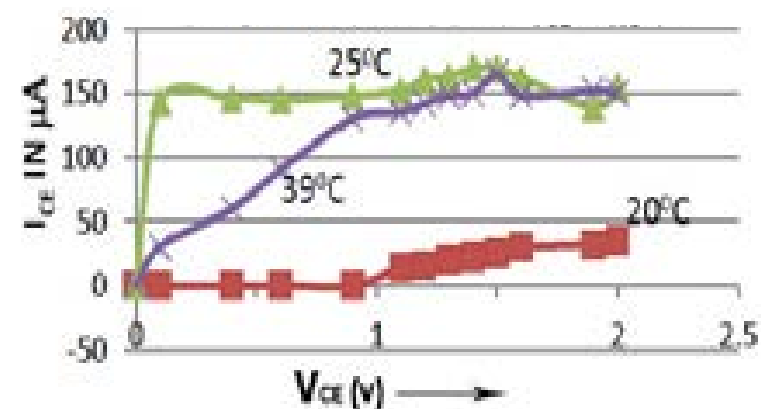

Chart 5B: Input charact (flow mode) probes spacing $\mathrm{d}=1.1 .1 .1,40 \mathrm{drops} /$ $\min , \mathrm{VCE}=3.0 \mathrm{~V}$. 
Citation: Kosta SP, Kosta YP, Bhatele M, Pandya K, Soni D, et al. (2014)Bio-Logical Human Tissue Based Electronic Circuits - An Alternate to Drug Therapy for Sick-Man (A Perspective Visionary Concept). J Bioengineer \& Biomedical Sci 3: 127. doi: 10.4172/2155-9538.1000127

Page 4 of 6

\section{Experimental setup ter kuman thin disse}

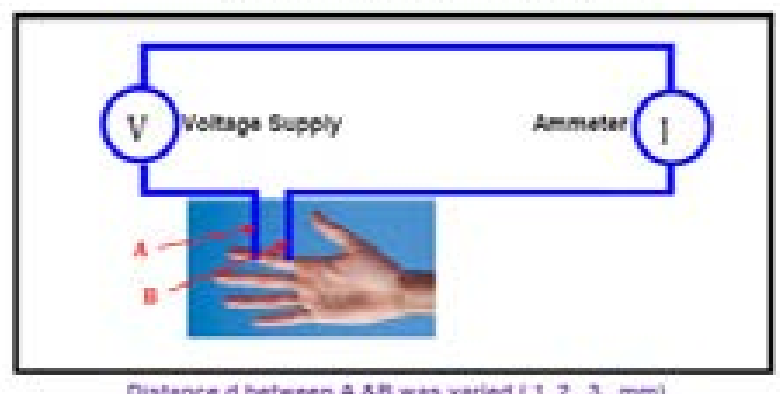

Diatunce d beteven A s, was varied $\{1,2,3, \mathrm{~mm}$

Figure 3A: Human skin based diode Configuration [3].[7].

\section{Probes pressed between thumb and first finger}

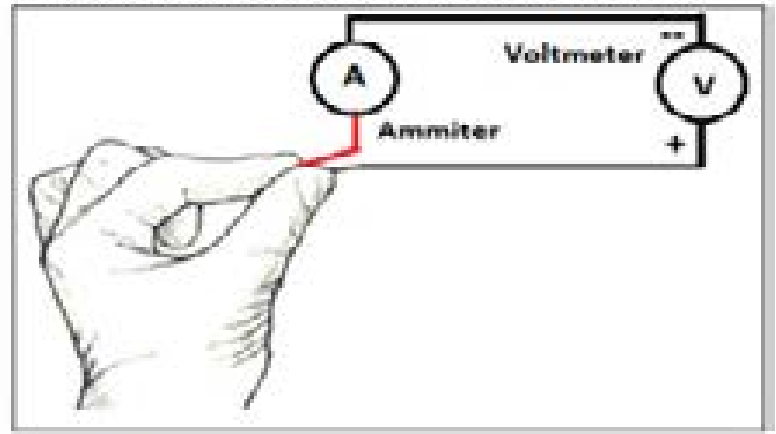

Figure 3B: Human skin based diode Configuration [8].
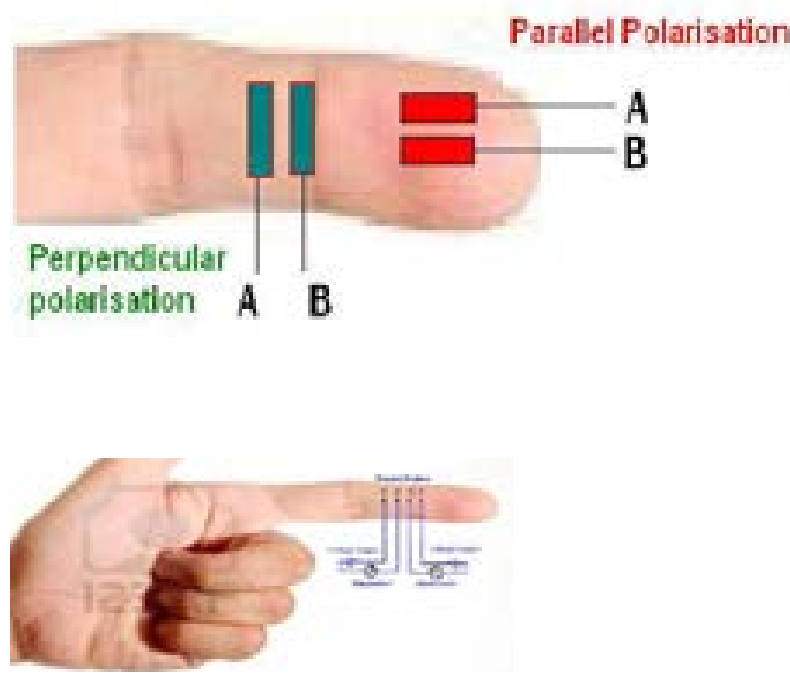

Figure 4: Human Tissue Skin Based Electronic Transistor HTSBET [8].

\section{Insight into fabrication technology}

Human tissues (blood capillaries, muscular cells, nerve and muscles cells, conducting militated axon - fiber, cell membranes of nerves etc.) proper geometrical dimensions, (realized by surgical - transplant operations) can be electrically/mechanically/chemically tuned to demonstrate/functions of R, C, L, diode and transistor. For example nerve fiber of various diameter and size demonstrate mechanical conduction velocity [6]. The nerve plays role in energy transfer and also in metabolism. It is also known that body fluids contain large quantities of electrolytes where the nerves in the body can function as a conducting transmitting channel (like conducting electrical wire).

\section{Description of the human tissue (two blood capillaries) based bio-electronic}

Amplifier circuit: Figure 7A depicts the theoretical electronic amplifier circuit made of discrete semiconductor components $\mathrm{CB}, \mathrm{RB}$ Transistor T, Coupling capacitor CL and biasing resistor RL along with

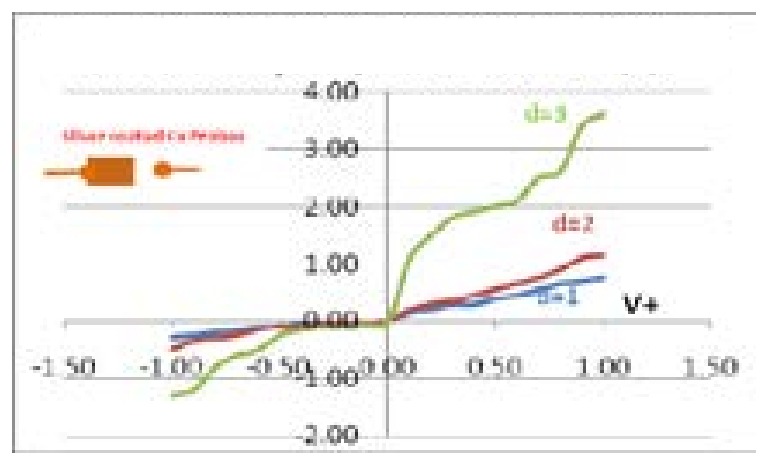

Chart 6A: V-1 charecteristics first finger skin based Diode rectangular silver coated Cu probes, variable distanced $d=1,2,3$.

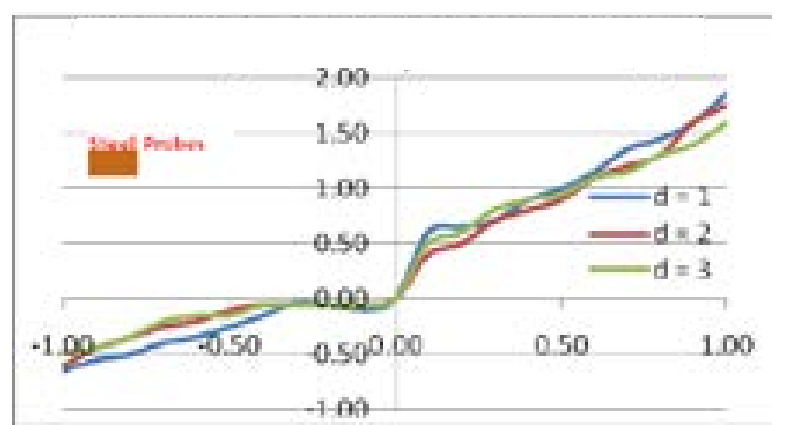

Chart 6B: V-1 charecteristicsof pressed first finger and thumb skin based Diode rectangular steel probes, variable distanced $d=1,2,3$.

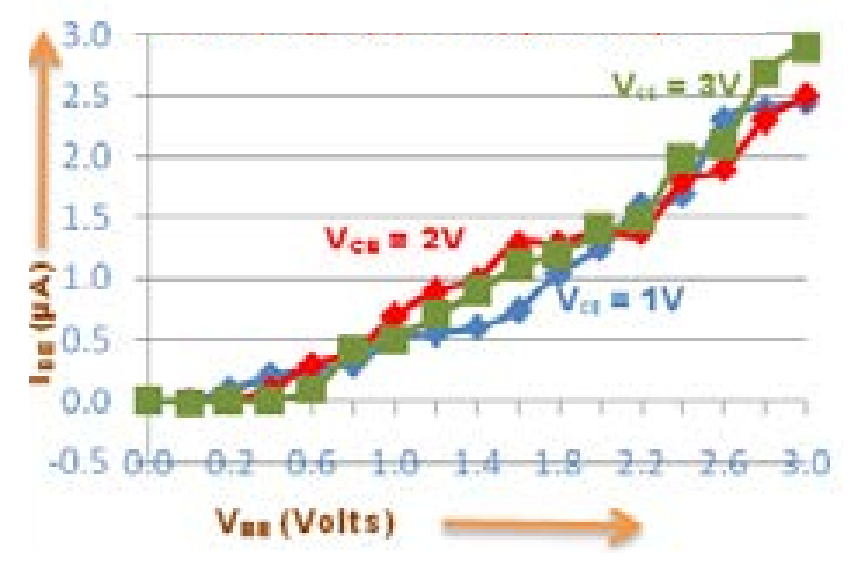

Chart 7A: HTSBET input charecteristics for $\mathrm{d}=2 \mathrm{~mm}, \mathrm{~V}_{\mathrm{CE}}=1,2,3$, Volt, parallel polari. 
Citation: Kosta SP, Kosta YP, Bhatele M, Pandya K, Soni D, et al. (2014)Bio-Logical Human Tissue Based Electronic Circuits - An Alternate to Drug Therapy for Sick-Man (A Perspective Visionary Concept). J Bioengineer \& Biomedical Sci 3: 127. doi: 10.4172/2155-9538.1000127

Page 5 of 6

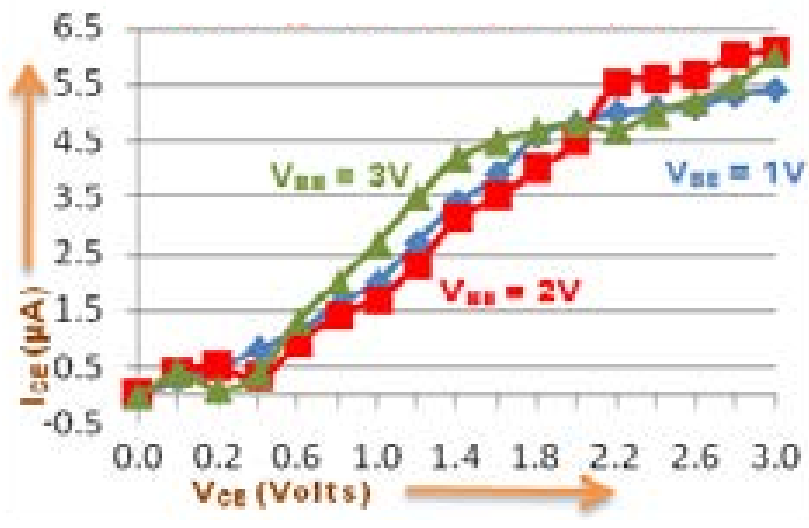

Chart 7B: HTSBET input charecteristics for $d=2 \mathrm{~mm}, \mathrm{~V}_{\mathrm{BE}}=1,2,3$, Volt, parallel polari.

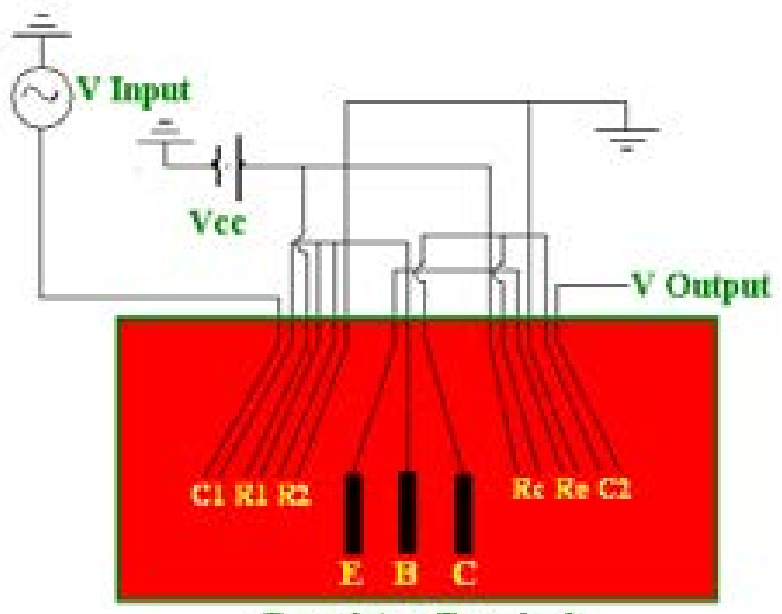

Transistor Terminals

Figure 5: FirstHumanTissueBloodLiquidICAmplifier.[9]

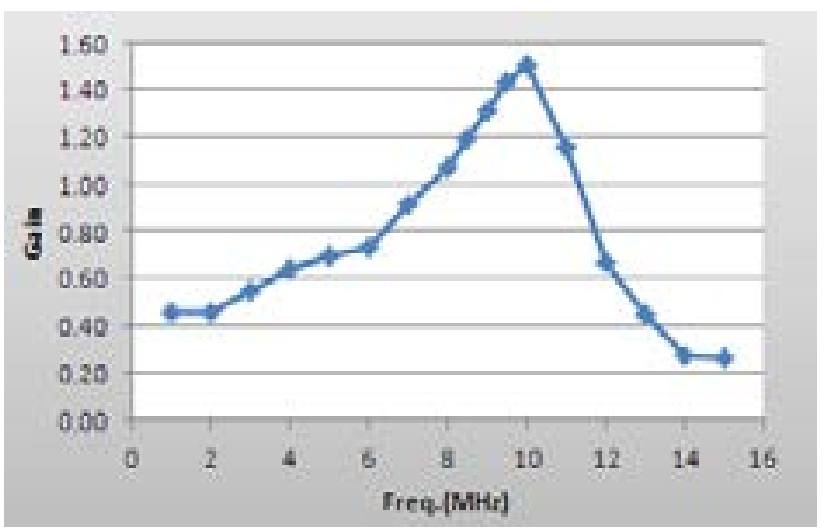

Chart: 8

voltage power supply terminals (positive \& negative earth terminal). The feedback from collector to base is due to shunt resistance RB. Figure 7B depicts a bio-electronic circuit made from two blood carrying thin capillary tubes. The discrete components of Figure 7A are realized in Figure 7B as under.

The bio transistor amplifier circuit: The four thin probe terminals $(1,2,3,4)$ inserted into the blood vessel capillary (like blood artery) represents the bio-transistor (probe 1 functions as base, probe 4 functions as collector, probes $2-3$ functions as earthed emitter). This configuration depicts two diodes forming a transistor in back to back

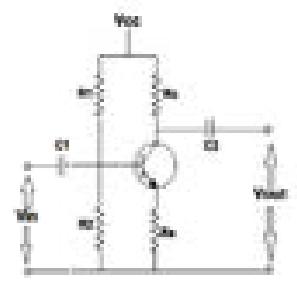

TheoreticalICAmplifier.[9]

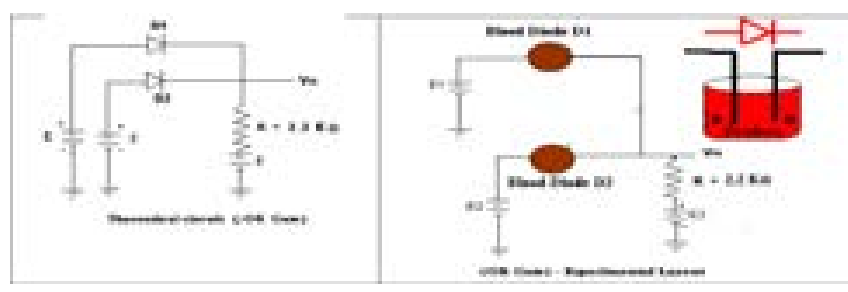

Figure 6: Logic Circuits OR \& AND gates.

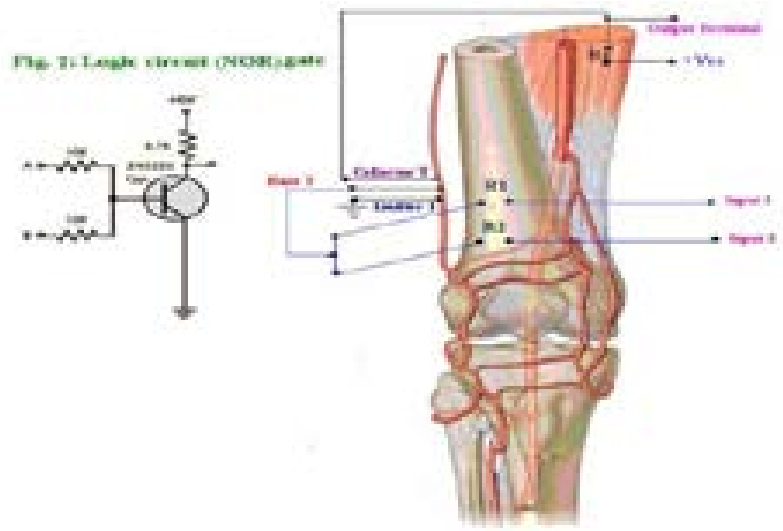

Figure 7: Logic circuit (NOR) gate.

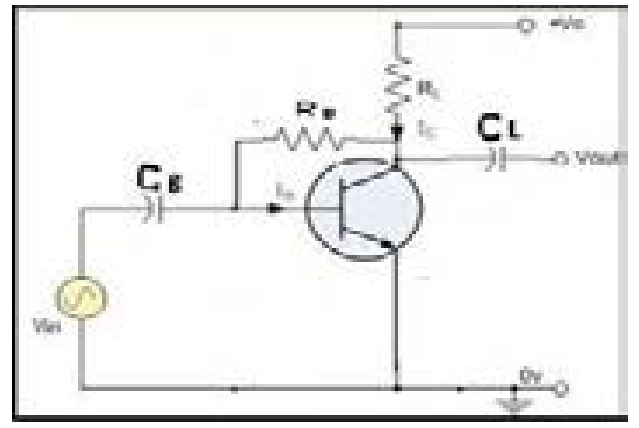

Figure 7A: Theoretical electronic amplifier circuit. 
configuration. The bio-transistor probe terminals are connected to various bio-resistances and capacitors $(\mathrm{CB}, \mathrm{RB}, \mathrm{CL}, \mathrm{RL})$ exactly shown in Figure 7A. The voltage supply VS \& VB are also incorporated in the circuit. Conventional electronic circuit input/output characteristic are realizable using VS \& VB (preferably below 2 Volts). We have already reported the realization of bio-electronic circuit components $(\mathrm{CB}, \mathrm{RB}$, CL, RL, Bio-transistor) and experimentally. Preliminary they function exactly similar to discrete semiconductor components.

The feedback in bio-transistor amplifier circuit layout (Figure 7A) can be explained using the Miller Effect Analysis. Feedback decreases the input and output impedances of the circuit.

Description of human palm based bio-electronic amplifier configuration: Figure 8 depicts the theoretical electronic amplifier circuit made of discrete semiconductor components resistances R1, $\mathrm{R} 2, \mathrm{Rc}$ and capacitor C. The Transistor is symbolically represented. The voltage supply Vin and Vout are also depicted. Figure 8 also depicts a bio-electronic amplifier circuit made of thin palm blood Capillaries / arteries. Here the bio-transistor is formed using blood carrying vessel (capillary on middle palm portion) with three thin probes depicting collector C, base B and emitter E (Earth). Resistances R1 and R2 (near end finger) and resistance and voltage bias resistor Rc (over the thumb) can be realized using arteries. The capacitor $\mathrm{C}$ connected to the base of bio-transistor amplifier is located at the end of thumb portion. I strongly foresee the realization of such live bio-electronic circuits using surgical methods in near future.

The ratio of resistances R1 \& R2 can be adjusted fix up the conventional operating point $\mathrm{Q}$ of amplifier. In bio- circuit application also these resistances may be adjusted like other conventional electronic amplifier. The R1and R2 used exclusively for operating point Q fixation.

Description of human leg joint based Bio-Electronic logic circuit NOR: Figure 9 depict a theoretical logic circuit and a feasible/ realizable human body leg joint based bio- electronic logic gate circuit. Here the theoretical circuit uses two 10k resistances in the input side to conventional semiconductor transistor $2 \mathrm{~N} 2222$ and resistance $4.7 \mathrm{k}$ in the output side. Power supply of $5 \mathrm{~V}$ also connected conventionally. The bio-electronics circuit can be realized using leg joint muscles, nerves, bones, blood capillaries /arteries along with harness using methodology described above (sub sections 5.1.1, 5.1.2). The two parallel resistances $10 \mathrm{k}$ and $10 \mathrm{k}$ are realizable on bone were as the bio-transistor (2N2222) can be realized on blood vessel capillary. The collector bias resister $4.7 \mathrm{k}$ can be realized at muscle/ flesh junction.

\section{Fabrication techniques}

Table 2 outlines some feasible conceptual fabrication technological

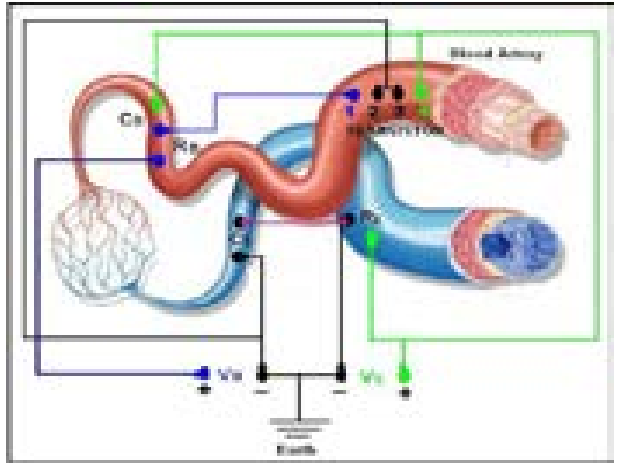

Figure 7B: Bio-electronic amplifier circuit.

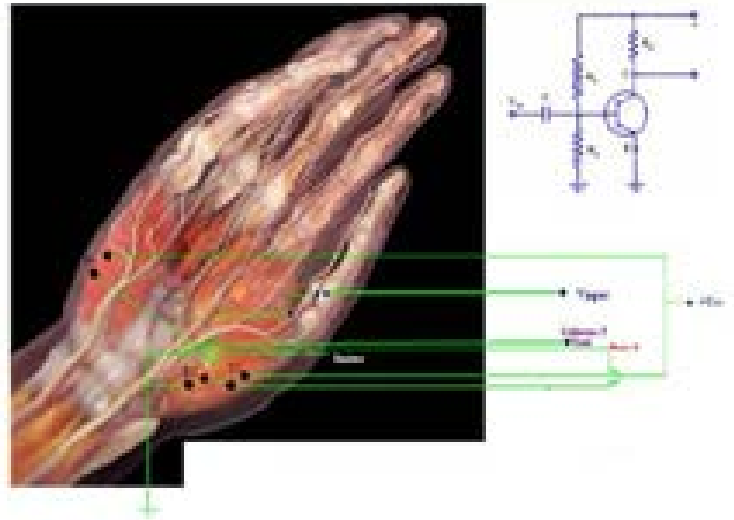

Figure 8: Human Palm tissues based Amplifier Configuration. Theoretical electronic amplifier circuit.

tips for realization of biological circuits inside the human body (tissues) using careful expert surgery techniques (methodology).

\section{Conclusion}

I. Using advance medical surgery techniques one can fabricate various constituent parts of HTBEC (from flexible capillaries, bones, muscles, nerves, etc.) at specified location inside human body. The supply voltage terminal can be brought to outside the human body that is on the human skin surface.

II. Toxic, other harmful effects HTBEC on the normal functioning of the human body system has to be studied in depth.

III. This concept can be first tried on animal or just dead body tissues.

IV. Selection of HTBEC location inside the human body is a complex difficult process and is a key to the success.

V. Application toward Cyborg implants, and simple diseases healing experimental studies are called for proving the concept.

\section{References}

1. Hugo Fricke, Sterne Morse (1925) The Journal of General Physiology 20: 153

2. Faes TJC, vanderMeij HA, deMunck JC, Heethaar RM (1999) Physiol Meas 20: R1-R10.

3. Kosta SP, Kosta YP, Bhatele M, Dubey YM, et al. (2011) "Human blood Liquid Memristor" Internationl Journal of Medical Engineering and Informatics 3: 16-29.

4. Kosta SP, Archana D,Prateek G, Preeti N, Shakti K, et al. (2013) "First Physical Model of Human Tissue Skin Based Memristor and their Network". International Journal of Medical Engineering and Informatics 5: 5-19.

5. Kosta SP (2012) Human blood Based Electronic Transistor. Int J Med Eng Inform 4: 373-386.

6. Gong WF (1898) "Review of Medical Physiology" Ganong's Review of Medical Physiology 4edn : 46-47.

7. Kosta SP, Kosta YP, Chaudhary JP, Vaghela PR, Mehta H, et al. (2012) "Biomaterial Human Body Part (Palm, Finger) based electronic FET Transistor" International Journal Bio-Medical Engineering and Technology 10: 368-382.

8. Kosta SP, Mukta B, Purnima S, Kosta YP, Kalpesh N, et al. (2012) "Human Tissue Skin Based Electronic Transistor". International Journal of Biomechatronics and Biomedical Robotics 12: 18-25.

9. Kosta SP "Feasibility study of electronic diode" accepted for publication in International Journal of Biomechatronics and Biomedical Robotics, InderScience Publication". 